\title{
The Protocol in Northern Ireland Law
}

\author{
GORDON ANTHONY
}

\subsection{Introduction}

This chapter provides an overview of the Protocol's position in Northern Ireland law. It does so by focusing on the 'legal hybridity' that results from the application of different legal rules under and outside the Protocol. While Northern Ireland is still formally a part of the UK, ${ }^{1}$ the reality is that its legal and political institutions now have obligations in relation to two constitutional orders. It is a point that will remain true for so long as the Protocol is in force: presently for four years, with the option of extension by 'democratic consent'.

The chapter has two main objectives. The first is to consider the nature of the legislative framework that has given effect to Brexit and how that intersects with the Northern Ireland Act 1998 (NI Act 1998). In terms, this is a point about overlapping 'constitutional statutes' and whether the Brexit legislation - principally the European Union (Withdrawal) Act 2018 (as amended) (EUWA 2018) - is consistent with all aspects of the Northern Ireland 'constitution' (ie, the BelfastGood Friday Agreement 1998 (1998 Agreement) and the NI Act 1998). ${ }^{3}$ Certainly, the Protocol is said in Article 1 to have the express objective of safeguarding the 1998 Agreement 'in all its dimensions', whether those relate to (for instance) the protection of rights ${ }^{4}$ or North-South co-operation. ${ }^{5}$ However, it has since been argued in proceedings in the domestic courts that aspects of the Northern Ireland constitution have been weakened by the legislation that gives domestic legal effect to the Protocol, in ways that contradict the logic of case law on constitutional

${ }^{1}$ NI Act 1998, s 1(1).

2 NI Act 1998, s 56A and Sch 6A.

${ }^{3}$ For the term 'constitution', see Robinson $v$ Secretary of State for Northern Ireland [2002] NI 390.

4 Protocol Art 2; NI Act 1998, ss 6(2)(ca), 24(1)(aa), 69(10A), 71, 74(7) and 78A-E.

5 Protocol Art 11; EUWA 2018, ss 8C(7) and 10. 
statutes. ${ }^{6}$ This chapter assesses the strength of those arguments and asks whether legal hybridity itself is contrary to parts of the Northern Ireland constitution.

The second objective is to consider the nature of the obligations that arise under and outside the Protocol. In the first instance, this is a point about the ongoing application of aspects of EU law in Northern Ireland, where Article 4(1) of the Withdrawal Agreement (WA) reads:

\begin{abstract}
The provisions of this Agreement and the provisions of Union law made applicable by this Agreement shall produce in respect of and in the United Kingdom the same legal effects as those which they produce within the Union and its Member States ... the United Kingdom shall ensure ... its judicial and administrative authorities [have powers] to disapply inconsistent or incompatible domestic provisions.
\end{abstract}

While the corpus of EU law that has effect in this way does so by reason of an international Treaty, Article 4 appears as a reformulation of the supremacy doctrine that was developed in case law such as Costa $v$ Enel and Simmenthal. ${ }^{7}$ This is where the legal hybridity of the Protocol takes form, as, to the extent that Northern Ireland's institutions are bound by norms of EU law under the Protocol, they must follow different rules when engaged in decision-making outside it. The chapter identifies the legal basis for the application of those different rules and 'who' must do 'what', and 'when', as a matter of Northern Ireland law.

\title{
10.2 The EUWA 2018 and the Protocol
}

The legal hybridity that has been created by the Protocol starts with EUWA 2018, as amended by the European Union (Withdrawal Agreement) Act 2020 (EUWAA 2020). The first purpose of EUWA 2018 is, of course, to make provision for the domestic law effects of Brexit, where it governs decision-making outside the Protocol not just in Northern Ireland but in the UK more widely. The relevant sections of the Act are considered in Chapter 9 in this volume, ${ }^{8}$ and only the following features are noted here: (i) the Act of 2018 expressly repealed the European Communities Act 1972 (ECA 1972) but kept many aspects of EU law on the statute book as 'retained EU law';' (ii) the principle of

\footnotetext{
${ }^{6}$ On which see Thoburn $v$ Sunderland CC [2003] QB 151.

7 Respectively, Case 6/64, [1964] ECR 585 and Case 106/77, [1978] ECR 629.

${ }^{8}$ Chapter 9.

${ }^{9}$ Ss 1 and $2-7$.
} 
supremacy no longer applies on its original terms, albeit the courts can still have regard for rulings of the Court of Justice of the European Union (CJEU) when interpreting retained EU law; ${ }^{10}$ (iii) references to Article 267 of the Treaty on the Functioning of the European Union (TFEU) are not possible, and nor is the Charter of Fundamental Rights (CFR) a part of domestic law; ${ }^{11}$ (iv) retained EU law can be modified by the devolved institutions in Northern Ireland in areas within their competence but not where particular aspects of EU law are specified in regulations made by a minister of the Crown; ${ }^{12}$ and (v) the general principles of EU law now have only a limited reach in domestic law and, post-Brexit, Francovich actions are not possible. ${ }^{13}$

The primary provision of the EUWA 2018 in terms of decisionmaking under the Protocol is section 7A, inserted by EUWAA 2020. Titled 'General implementation of remainder of withdrawal agreement', this section provides: '(2) The rights, powers, liabilities, obligations, restrictions, remedies and procedures [in the WA] are to be - (a) recognised and available in domestic law, and (b) enforced, allowed and followed accordingly'; and '(3) Every enactment (including an enactment contained in this Act) is to be read and has effect subject to subsection (2)'.

The full significance of section 7A becomes apparent when it is read beside Article 4(1) WA (above) and Articles 12(4) and 13(2)-(4) of the Protocol, as these embed EU law (including its general principles and remedies) into the law of Northern Ireland. Article 4(1)'s specific effect is thus to make the provisions of EU law listed in the Protocol applicable in Northern Ireland, where Article 12(4) provides, as regards Articles 5 and 7-10 of the Protocol (and their Annexes), that the CJEU 'shall have the jurisdiction provided for in the Treaties in this respect. The second and third paragraphs of Article 267 TFEU shall apply to and in the United Kingdom in this respect.' Article 13(2)-(4) in turn reads:

[T] he provisions of this Protocol referring to Union law or to concepts or provisions thereof shall in their implementation and application be interpreted in conformity with the relevant case law of the [CJEU] ... [W] here this Protocol makes reference to a Union act, that reference shall be read as referring to that Union act as amended or replaced ... [T] he [EU may adopt] a new act that falls within the scope of this Protocol, but which

\footnotetext{
${ }^{10} \mathrm{~S} 5$.

11 Ss $5(4)$ and 6(1)(b).

12 Ss 7 and 12 (and NI Act 1998, s 6A).

${ }^{13}$ Sch 1.
} 
neither amends nor replaces [an EU] act listed in the Annexes to this Protocol.

Section 7A is not the only provision of EUWA 2018 that gives effect to the Protocol - for instance, section 8C confers on ministers of the Crown wide regulation-making powers in relation to it, and section 10 (on protection for North-South co-operation) was amended in the light of Article 11 of the Protocol. ${ }^{14}$ However, for the purposes of legal hybridity, section $7 \mathrm{~A}$, as read with the Act more generally, establishes the different sets of rules that must be followed by Northern Ireland's institutions, including its courts. While it might be argued that such hybridity is simply a carry-over of the hybridity that applied under the ECA 1972 where UK courts frequently observed different procedural and substantive rules ${ }^{15}$ - the fact that aspects of EU law now apply in only Northern Ireland means that the analogy is not a perfect one. In short, while EU law had previously applied throughout the UK as a whole and in the light of the wider devolution settlement, the Protocol has placed Northern Ireland in a truly unique position. Indeed, it may, on one reading, even be queried whether 'legal hybridity' is a strong enough descriptor: economic constitutionalism and the EU's historical experience with sectoral integration might suggest that something more fundamental is afoot. ${ }^{16}$

\subsection{The NI Act 1998 and the Protocol}

The Protocol has also been implemented through amendment of the NI Act 1998 - and some parts of the Act can now be understood only when read alongside provisions of EUWA 2018. While it is arguable that the 'catch-all' nature of section 7A EUWA 2018 would have made all necessary changes by implication (albeit that would raise a question about the interplay of 'constitutional statutes'; see Section 10.4), the reality is that the complexities of the Protocol required further, specific changes to the NI Act 1998. Those complexities are, of course, a result of the

14 Note that the powers in s 8C correspond with powers for NI departments under s 11 of, and Sch 2 to, the Act. On the nature of s 10 EUWA 2018, see Re McCord/JR83/Waring [2019] NICA 49.

15 See, eg, $R$ v Ministry of Agriculture, Fisheries and Food, ex p First City Trading [1997] 1 CMLR 250; and G Anthony, UK Public Law and European Law: The Dynamics of Legal Integration (Hart 2002) chs 4-6.

${ }^{16}$ On sectoral integration, see, eg, Arne Niemann and Philippe C Schmitter, 'Neofunctionalism' in Antje Wiener and Thomas Diez (eds), European Integration Theory (2nd edn, Oxford University Press 2009) ch 3. 
complexities of the 1998 Agreement itself, as the Protocol is intended to protect that Agreement 'in all its dimensions'. ${ }^{17}$ Four provisions of the Protocol in this regard are of particular importance.

The first provision is Article 2, which relates to the protection of rights and, as a result of sections 6(2)(ca) and 24(1)(aa) of the NI Act 1998, now limits the powers of the devolved institutions. The implications of that Article are considered in more detail in a subsequent chapter and will not be analysed in any depth here. ${ }^{18}$ However, one point that can be made concerns the CFR and the range of Directives that is listed in Annex I to the Protocol. This is one area where the dynamism of the CFR might well continue to be evident in Northern Ireland law, as the CJEU may draw upon it if required to rule upon the meaning of the Directives - or, indeed, new Directives within the scope of the Protocol - in the future. ${ }^{19}$ In the event that it were to do so, the Northern Ireland courts would be required to follow that case law by reason of Article 13(2), which states that: 'the provisions of this Protocol ... shall in their implementation and application be interpreted in conformity with the relevant case law of the [CJEU]'. The contrast with the position under section 5 EUWA 2018 which provides that the CFR does not apply in UK law more generally could well become of more than passing significance.

The second provision is Article 11, which states that the Protocol 'shall be implemented and applied so as to maintain the necessary conditions for continued North-South cooperation, including in the areas of environment, health, agriculture, transport, education and tourism, as well as in the areas of energy, telecommunications, broadcasting, inland fisheries, justice and security, higher education and sport'. This is one area where the NI Act 1998 is to be read alongside EUWA 2018, as section 10 of that Act (among others) safeguards the multilayered arrangements that underlie North-South co-operation. Such co-operation was envisaged by Strand Two of the 1998 Agreement (as supported by the British-Irish Agreements of 1998 and 1999), and it takes form in Northern Ireland law in, inter alia, a ministerial duty to participate in meetings of the North-South Ministerial Council, and the possible exercise of legislative powers in relation to agreements reached there. ${ }^{20}$ The multilayered nature of these arrangements is such that the legal structures for co-operation are found in

17 Art 1. On the 1998 Agreement, see Chapter 2.

18 See Chapter 12.

19 See further Chapter 13. On the dynamic nature of the CFR, see AB v Facebook [2013] NIQB 14, para 14, McCloskey J.

20 NI Act 1998, s 52B and Sch 2, para 3. 
international law but with a basis in political agreement in Northern Ireland, and this is where section 10 EUWA 2018 becomes significant. Originally enacted before the Protocol was agreed, it was amended in its light and now does three main things: (1) it imposes a duty on ministers of the Crown and Northern Ireland ministers and departments to act compatibly with the NI 1998 when exercising powers under EUWA 2018; (2) it prohibits ministers of the Crown from making regulations which would diminish any form of North-South co-operation as provided for by the 1998 Agreement or which would facilitate physical border infrastructure on the island of Ireland; and (3) it prohibits a minister of the Crown from agreeing to any recommendation by the Protocol's Joint Committee (JC) that would alter the arrangements for North-South co-operation in the 1998 Agreement, establish a new implementation body, or alter the functions of an existing implementation body. Point (3) would suggest that any such changes would be possible only through a further British-Irish agreement, where previous agreements have been contingent upon political agreement within Northern Ireland itself. ${ }^{21}$

The third provision is Article 13(4). This envisages the adoption by the EU of an act which may either amend or replace existing acts in the Protocol or be in the form of a new act 'that falls within the scope of this Protocol'. This is where the Protocol is arguably at its most controversial in terms of democratic principle, as it gives the UK government only a peripheral role in relation to such acts and attributes no role at all to the Northern Ireland institutions. Domestic law does, however, oblige those institutions to track developments in relation to Articles 2, 5 and 7-10 of the Protocol, where the Secretary of State has a power under section 26(2) of the NI Act 1998 to make an order in relation to the discharge of international obligations. While it is, of course, unclear quite how those obligations will develop in the future, they lend themselves to a more general point about the Northern Ireland institutions existing as 'ruletakers' under the Protocol, rather than as 'rule-makers'. They are, moreover, rule-takers who could potentially be liable for 'sufficiently serious' breaches of EU law in accordance with the 'Francovich' principle - such is the combined effect of Article 4(1) WA and section 7A(2) EUWA 2018.

${ }^{21}$ See, to similar effect, s 8C of EUWA 2018 whereby a power for ministers of the Crown to make regulations in relation to the Protocol does not extend to 'the second sentence of Article 11(1) of the Protocol (which provides that the United Kingdom and the Republic of Ireland may continue to make new arrangements that build on the provisions of the Belfast Agreement in other areas of North-South cooperation on the island of Ireland)'. 
The fourth provision is Article 18, which is titled 'Democratic consent in Northern Ireland'. This Article provides that, four years after the end of the transition period, the UK government must 'seek democratic consent in Northern Ireland in a manner consistent with the 1998 Agreement' for the continued application of Articles 5-10 of the Protocol. A number of possible outcomes are envisaged by the Article: (i) a majority of members of the Northern Ireland Assembly (the Assembly) may vote to continue the application of Articles 5-10, in which instance they will apply for a further four years; (ii) there is 'cross-community' support (ie, majority support within unionism and nationalism) for the continued application of Articles 5-10, in which instance they will apply for a further eight years; and (iii) a majority of members of the Assembly may vote not to continue the operation of Articles 5-10. In this third instance, Articles 5-10 will remain in force for a further two-year period during which time the JC must make recommendations about future arrangements 'taking into account the obligations of the parties to the 1998 Agreement'.

The mechanisms for obtaining such consent are a matter for the UK alone, ${ }^{22}$ and the NI Act 1998 has since been amended by regulations made under EUWA 2018. ${ }^{23}$ The primary amendments are found in Schedule 6A to the NI Act 1998, which makes provision for a 'default democratic consent process ${ }^{24}$ and an 'alternative democratic consent process' ${ }^{25}$ Of particular note is paragraph 18 of the Schedule, which 'applies in relation to any motion for a consent resolution whether the default democratic consent process or the alternative democratic consent process is applicable. ${ }^{26}$ According to that paragraph, the Assembly may vote on a consent motion only once and, by paragraph 18(5), section 42 of the NI Act 1998 'does not apply in relation to a motion for a consent resolution'. Section 42 governs the 'petition of concern' mechanism whereby either of Northern Ireland's two main ethno-national groups can veto measures with which they disagree, and the regulations that inserted Schedule 6A have thus written out a key feature of the original 1998 Agreement. The significance of this point is returned to in Section 10.4.

22 See the UK government's related 'Unilateral Declaration on Democratic Consent', https://assets.publishing.service.gov.uk/government/uploads/system/uploads/attach ment_data/file/840232/Unilateral_Declaration_on_Consent.pdf.

23 The Protocol on Ireland/Northern Ireland (Democratic Consent Process) (EU Exit) Regulations 2020 (SI 2020/1500).

${ }^{24}$ Part 3: to apply when the offices of the First Minister and deputy First Minister are filled.

${ }^{25}$ Part 4: to apply when the offices of the First Minister and deputy First Minister are vacant.

${ }^{26}$ Para 17. 


\subsection{Constitutional Statutes and the Protocol}

The remaining matter to be addressed in this chapter is how to conceive of the interplay between EUWA 2018 and the NI Act 1998. As noted in the introduction, this is a point about 'constitutional statutes' and how far that imagery can illuminate the relationship between the Acts. The term is famously associated with Laws LJ's ruling in Thoburn, where he said:

[A] constitutional statute is one which (a) conditions the legal relationship between citizen and state in some general, overarching manner, or (b) enlarges or diminishes the scope of what we would now regard as fundamental constitutional rights[;] (a) and (b) are of necessity closely related: it is difficult to think of an instance of (a) that is not also an instance of (b). ${ }^{27}$

While Thoburn concerned the effects of ECA 1972 - which, as a constitutional statute, was said to lie beyond the rules of implied repeal - Laws LJ identified a list of other qualifying statutes that included Magna Carta, the Bill of Rights, the Union with Scotland Act 1706, the Human Rights Act 1998 and the devolution legislation for Scotland and Wales. ${ }^{28}$ It is a commonplace that the NI Act 1998 is also a constitutional statute. ${ }^{29}$

Two questions arise from this. The first is whether EUWA 2018 ought to be regarded as a constitutional statute, where it would appear that the answer can only be yes. Not only does EUWA 2018 have elements of both (a) and (b) from Laws LJ's definition; it has been enacted in the very constitutional space that was previously occupied by ECA 1972. Indeed, the similarities with ECA 1972 can be seen in the fact that section 7A EUWA 2018 has largely the same effects as section 2 ECA 1972 - a 'catchall' means of incorporation linked to a requirement to read 'all other enactments' in the light of the incorporated law. ${ }^{30}$ The similarities can also be seen in the fact that EUWA 2018 has replaced ECA 1972 as an 'entrenched enactment' under section 7 of the NI Act 1998. This means that EUWA 2018 'shall not be modified by an Act of the Assembly or

27 Thoburn $v$ Sunderland CC [2003] QB 151, 187, [62]. For subsequent judicial reference to Thoburn, see, eg, $R$ (Buckinghamshire CC) $v$ Secretary of State for Transport [2014] UKSC 3, [2014] 1 WLR 324, 382-83, [208], Lords Mance and Neuberger; and R (Privacy International) $v$ Investigatory Powers Tribunal [2019] UKSC 22, [2020] AC 491, 544,

28 Ibid.

29 Robinson (n 3), describing the NI Act 1998 as a 'constitution for Northern Ireland'.

30 On s 2 of ECA 1972, see R $v$ Secretary of State for Transport, exp Factortame (No 2) [1991] 1 AC 603. 
subordinate legislation made, confirmed or approved by a Minister or Northern Ireland department'. ${ }^{31}$

The second question is what does this all mean in practice? Certainly, much will depend on how the courts regard Laws LJ's statement about constitutional statutes not being subject to implied repeal, and repeal being possible only through the use of 'express words'. While the outworkings of this are uncontroversial when a constitutional statute is succeeded by an 'ordinary' Act of Parliament, the position is more complex where one constitutional statute (the NI Act 1998) has points of cross-over with another constitutional statute (EUWA 2018). The point can again be developed with reference to section 7A EUWA 2018, as the rules on implied repeal would mean that, were there to be any conflict between the WA and the NI Act 1998, the WA would automatically prevail. However, the difficulty with that approach is that it inverts the logic of Thoburn, unless it can be said that Laws LJ intended for his statement of principle to apply at only the interface between 'constitutional' and 'ordinary' statutes. There is nothing in the judgment to suggest that he intended for it to be limited in that way.

These are not simply points of abstract interest, as related questions about constitutional statutes are presently before the courts in Northern Ireland. ${ }^{32}$ While the issue of implied repeal has arisen in those proceedings in the context of a challenge to the Protocol's effects on the Act of Union between Ireland and Britain, the proceedings also challenge the lawfulness of the regulations that inserted Schedule 6A into the NI Act 1998. As already discussed, those regulations have written out the 'petition of concern' mechanism from the democratic consent process and, in so doing, have modified a key feature of the Northern Ireland constitution. Although there are strong practical reasons for limiting the petition's effects in this way - its use could potentially frustrate any future consent motion within the Assembly - the more fundamental point is whether it ought to be possible to change a constitutional statute by way

31 NI Act 1998, s 7(1)(e), as inserted by para 51(2) of Sch 3 to EUWA 2018.

${ }^{32}$ In the matter of an Application by Allister, et al [2021] NIQB 64 (challenge by several Unionist politicians to the constitutionality of the Protocol rejected by High Court). This case is considered further in 'Update: Developments from July 2021 to September 2021' at the front of this book. Whether the High Court decision will be appealed was uncertain at the time of writing (July 2021). For other case law on the interface between constitutional statutes, see $R$ (Counsel General for Wales) $v$ Secretary of State for Business, Energy and Industrial Strategy [2021] EWHC 950 (Admin) (application for judicial review of the question as to whether the United Kingdom Internal Market Act 2020 impliedly limiting the legislative competence of the Senedd was premature). 
of regulations made under another constitutional statute. Prior to Brexit, the case law on devolution may well have suggested that this should not be possible, as the courts had acknowledged the importance of the devolution settlement throughout the UK and its localized, democratic basis. ${ }^{33}$ However, the case law since Brexit has equally seen the courts return to a more absolutist view of the Westminster Parliament's powers and, in particular, a Diceyan view of legal sovereignty. ${ }^{34}$ It is a retreat that may ultimately answer all questions in favour of the most recent constitutional statutes.

\subsection{Conclusion}

This chapter began by noting that it had two main objectives: to consider the nature of the legislative framework that has given effect to Brexit and how that intersects with the NI Act 1998; and to consider the nature of the obligations that arise under and outside the Protocol. It has referred throughout to 'legal hybridity' and the idea that the Northern Ireland institutions must observe different rules under and outside the Protocol. In terms of the Assembly and the Executive, this means that they are able to modify aspects of 'retained EU law' in matters outside the Protocol but that, in matters under the Protocol, they are bound by the first principles of EU law in relation to all provisions of the Protocol. In terms of the courts, EU law no longer applies on its original terms in cases outside the Protocol, but it does apply with its full force in cases under it. At its height, this means that the courts must apply the supremacy principle, observe the CFR, make Article 267 TFEU references in relation to issues arising under Article 5, 7-10 and 12(2) of the Protocol, apply the general principles of EU law, and hear Francovich claims.

Is this legal hybridity inconsistent with the Northern Ireland constitution? Much of the answer to this question will be found in the ongoing proceedings before the Northern Ireland courts, where historical and contemporary dimensions to the constitution are in issue. Should the

${ }^{33}$ R(Jackson) v Attorney-General [2005] UKHL 56, [2006] 1 AC 262, 302, [102], Lord Steyn; Axa General Insurance v HM Advocate [2011] UKSC 46, [2012] 1 AC 868; Re Recovery of Medical Costs for Asbestos Diseases (Wales) Bill [2015] UKSC 3, [2015] AC 1016, 1059-60, [118-22], Lord Thomas.

${ }^{34} R$ (Miller) $v$ Secretary of State for Exiting the European Union [2017] UKSC 5, [2018] AC 61; and UK Withdrawal from the European Union (Legal Continuity) (Scotland) Bill [2018] UKSC 64, [2019] AC 1022. 
courts ultimately hold that the Protocol and its means of implementation have breached foundational constitutional principle, the EU and the UK may well be required to revisit the international law basis of their future relationship. In the event that the courts rule that the Protocol is not inconsistent with the Northern Ireland constitution, legal hybridity may become one of its defining features. 